\title{
Open Partial Nephrectomy With Zero Ischemia Technique Using Thulium Laser: Our Experience of 4 Cases
}

\author{
Kumar Prem, Pankaj Kumar, Zia Ur Rehman, Somesh Janoria \\ Ranchi Urology Centre, Buxi Compound, Bariatu, Ranchi, Jharkhand, India
}

\begin{abstract}
With the advent of newer technologies, the management of small renal masses has shown a paradigm shift. This has resulted in preferring partial nephrectomy over radical nephrectomy, emphasizing the concept of nephron sparing surgery. Various lasers have been used in few cases. We prospectively evaluated the use of thulium laser in open partial nephrectomy over last 1 year. The aim is to study thulium laser as an energy source for partial nephrectomy for peripheral tumor. The role of partial nephrectomy and zero ischemia time in renal preservation is already proven. Outcomes of total of 4 patients who underwent open partial nephrectomy were analyzed prospectively. We used Quanta Cyber TM laser at setting of $30 \mathrm{~W}$ both for cutting and coagulation. Preoperative characteristics and outcomes were analyzed. Four patients underwent open partial nephrectomy with zero ischemia. The mean tumor size was $5.26 \mathrm{~cm}$, mean RENAL nephrometry score was 4.5 , mean operative time was 67.5 minutes, active laser time was 2 minutes, mean blood loss related to partial nephrectomy per se was $65 \mathrm{~mL}$. Mean preoperative hemoglobin was $11.12 \mathrm{~g} \%$ and mean postoperative hemoglobin was 10.05 $\mathrm{g} \%$. Mean duration of stay was 6 days. Histologically all lesions were renal cell carcinoma pT1/T2, with margins negative for tumor and no deterioration in renal function during follow-up. The thulium laser at $2013 \mathrm{~nm}$ wavelength demonstrates excellent hemostasis and precise cutting capabilities of the renal cortex during open partial nephrectomy for peripheral tumors without requiring renal artery clamping. (Korean J Urol Oncol 2020;18:155-160)
\end{abstract}

Key Words: Open partial nephrectomy • Zero ischemia - Nephron sparing surgery $\cdot$ Thulium laser

The role of partial nephrectomy in T1 tumor and selected $\mathrm{T} 2$ tumors for preservation of functional renal tissue is well established. It provides equivalent oncological efficacy as compared to radical nephrectomy. ${ }^{1-3}$ During partial nephrectomy, hilar clamping is required for keeping the operative area bloodless for precise excision of the tumor till the renorrhaphy is done. Hilar clamping leads eventually to ischemic injury to renal tissue thereby compromising the

Received May 15, 2020, Revised Jul 15, 2020,

Accepted August 5, 2020

Corresponding Author: Somesh Janoria

Registrar, Ranchi Urology Centre, Buxi Compound, Bariatu, Ranchi, Jharkhand 834009, India

E-mail: someshjanoria@gmail.com

Tel: $+91-6512546333$

ORCID: https://orcid.org/0000-0001-9366-1147 functional outcome. ${ }^{4,5}$ There are many techniques that are being evaluated to achieve zero ischemia in partial nephrectomy, which includes selective renal artery or renal parenchymal clamping, radiofrequency ablation, hydro-jet assisted technique, preplaced suture renorrhaphy technique, and lasers. ${ }^{6}$ Gill et al. ${ }^{7}$ have reported a novel technique which incorporates selective branch microdissection of renal artery or vein into renal sinus simultaneously creating transient pharmacologically induced intraoperative hypotension.

Laser technologies like Diode and Holmium lasers have been used in few cases for partial nephrectomy with reduced warm ischemia time. ${ }^{8,9}$ Thulium laser has been used in open and laparoscopic partial nephrectomy with zero ischemia in limited patients. ${ }^{10,11}$ Thulium laser came into

This is an Open Access article distributed under the terms of the Creative Commons Attribution Non-Commercial License (http://creativecommons.org/licenses/by-nc/4.0/) which permits unrestricted non-commercial use, distribution, and reproduction in any medium, provided the original work is properly cited. 2020 (C) Copyright The Korean Urological Oncology Society and The Korean Prostate Society. All Rights Reserved. 
practice in 2005 and having wave length of $2013 \mathrm{~nm}$, and penetrating depth of $0.2 \mathrm{~mm}$, offers complete absorption of energy in water in continuous wave mode..$^{12,13}$

We prospectively studied the role of thulium: YAG laser (Quanta Cyber TM laser) as an energy source to perform open partial nephrectomy with zero ischemia and tumor-free margin in patients with exophytic tumors (pT1, pT2) in at our center in last 1 year.

\section{CASE REPORT}

\section{Patients and Methods}

We used 2013 nm, thulium: YAG laser (Quanta Cyber TM laser, Milan, Italy). Data was collected prospectively. Patients were selected for open partial nephrectomy after preoperative evaluation was done in outpatient department including history taking, physical examination, and routine investigation. All patients underwent abdominal contrast tomography scan with 5-mm axial cuts. Pre- and intraoperative characteristics, and postoperative outcomes were collected and analyzed (Tables 1, 2). Preoperative RENAL nephrometry scoring was also done (Table 3). RENAL nephrometry scoring system is used to grade the renal tumor into low to high complexity using contrast cross-sectional tomography images. Its purpose is to help surgeons in counseling the patients, surgical planning and further follow-up. ${ }^{14}$ We analyzed the results of 4 cases operated at different dates at our center.

\section{Open Partial Nephrectomy Technique Using Thulium Laser}

We used thulium laser at $30 \mathrm{~W}$ for cutting and coagulation (Fig. 1). Renal vessels were slinged with loop as a preparation to control accidental bleeding (Fig. 2). The surface marking of the tumor was done using the laser and the incision made around the mass (Fig. 3). The mass was then separated from the adjoining cortex by using laser in continuous mode for cutting while giving gentle traction (Fig. 4). Hemostasis was achieved with intermittent coagulation to seal small vessel less than 1.5 to $2 \mathrm{~mm}$. The field was kept continuously irrigated with normal saline to avoid the surface temperature to rise from the heat of the laser along with keeping the area clean (Fig. 4). Under running of discrete vessels at the base of the fossa was done by using
Table 1. Preoperative, intraoperative characteristics, postoperative, and pathological outcomes

\begin{tabular}{lc}
\hline \multicolumn{1}{c}{ Variable } & Value \\
\hline No. of patients & 4 \\
Age (yr), mean (range) & $53.5(34-64)$ \\
Side, left:right & $4: 0$ \\
Tumor size (cm), mean (range) & $5.26(3-11)$ \\
Tumor complexity (exophytic) & 4 \\
RENAL score & $4.5(4-6)$ \\
Smoking/addiction & 1 \\
Warm ischemia time (min) & Nil \\
Operating time (min), mean (range) & $67.5(60-90)$ \\
Active laser time (min), mean (range) & $2.25(2-3)$ \\
Blood loss, related to partial nephrectomy & $65(50-100)$ \\
per se (mL), mean (range) & \\
Patient requiring PCS repair & Nil \\
Hospital stay (day), mean (range) & $6(5-7)$ \\
Follow-up (mo) & $1 \&$ months \\
Serum creatinine (mg/dL) & \\
Preoperative & $1.16(1-1.42)$ \\
Postoperative & $1.25(1.17-1.56)$ \\
Hemoglobin (g\%), mean (range) & \\
Preoperative & $11.12(9.8-12.70)$ \\
Postoperative & $10.05(8.4-11.8)$ \\
Histopathological outcome & \\
Malignant & 4 \\
Stage, T1:T2 & $3: 1$ \\
Positive margins & 0 \\
\hline
\end{tabular}

PCS: Pelvi Calicyeal System.

polyglactin 910 (Ethicon vicryl) 3-0. Renorrhaphy was done in standard manner (Fig. 5). All the cases were done using no hilar clamping technique and hence zero ischemia time.

\section{Results}

All 4 patients successfully underwent open partial nephrectomy. Ischemia time was zero in all cases. None of them required clamping during any stage of surgery. Postoperative stay was uneventful in all 4 patients. The mean tumor size was $5.26 \mathrm{~cm}$ (range, 3-11 cm), mean RENAL score was 4.5 (range, 4-6), mean operative time was 67.5 minutes (range, 60-90 minutes), active laser time was 2.25 minutes (range, 2-3 minutes), and mean blood loss related to partial nephrectomy per se was $65 \mathrm{~mL}$ (range, 50$100 \mathrm{~mL}$ ). Mean preoperative hemoglobin was $11.12 \mathrm{~g} \%$ (range, 9.8-12.70 $\mathrm{g} \%$ ) and mean postoperative hemoglobin was $10.05 \mathrm{~g} \%$ (range, $8.4-11.8 \mathrm{~g} \%$ ). Mean duration of stay was 6 days (range, 5-7 days). Wound examination was done 


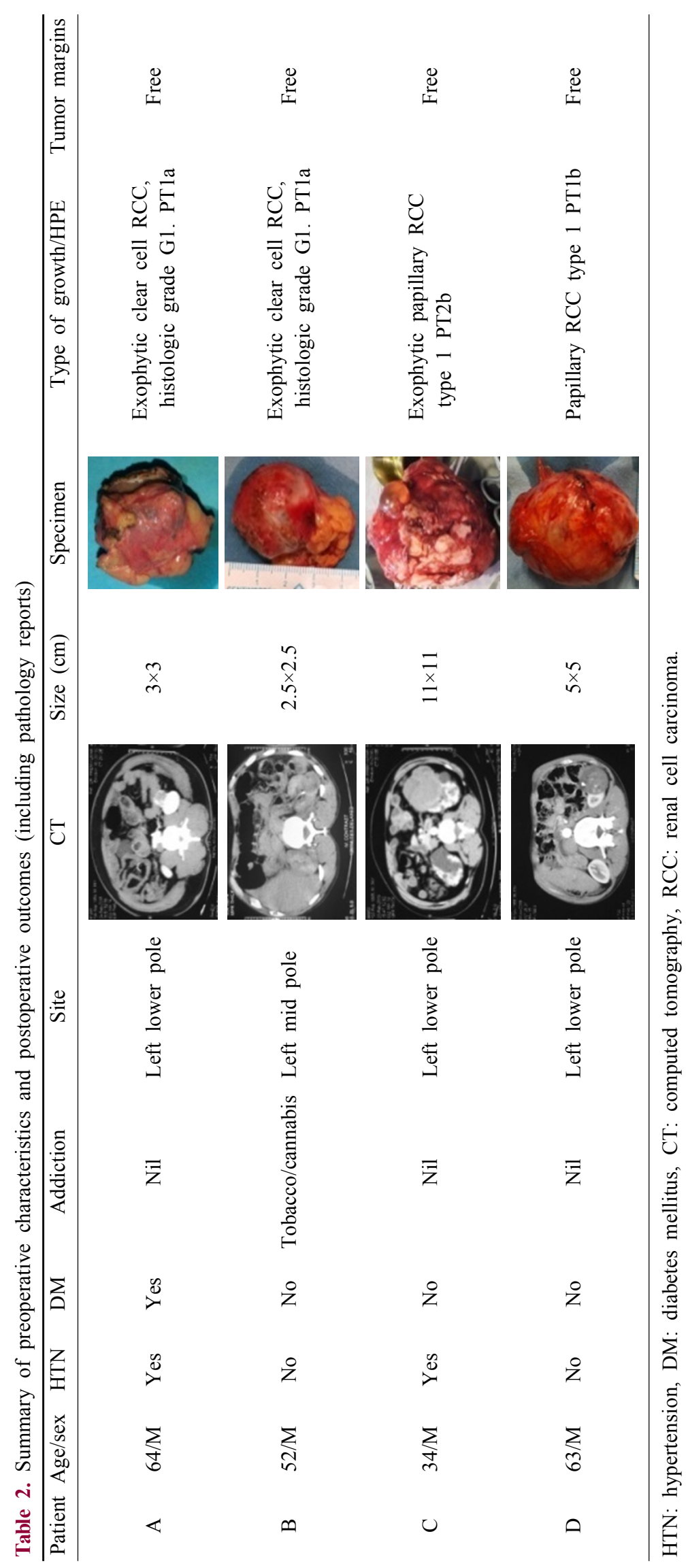


Table 3. RENAL nephrometry score ${ }^{14}$

\begin{tabular}{|c|c|c|c|c|c|}
\hline RENAL & Patient 1 & Patient 2 & Patient 3 & Patient 4 & Mean (range) \\
\hline Radius (maximum diameter in $\mathrm{cm}$ ) & 1 & 1 & 3 & 1 & \\
\hline Exophytic/endophytic & 1 & 1 & 2 & 1 & \\
\hline Nearest sinus/PCS (mm) & 1 & 1 & 1 & 1 & \\
\hline Anterior/posterior & $\mathrm{P}$ & $\mathrm{P}$ & $\mathrm{P}$ & $\mathrm{P}$ & \\
\hline Location with respect to polar line & 1 & 1 & 2 & 1 & \\
\hline Total & 4 & 4 & 6 & 4 & $4.5(4-6)$ \\
\hline
\end{tabular}

PCS: Pelvi Calicyeal System.



Fig. 1. Showing thulium laser at $30 \mathrm{~W}$ (cutting and coagulation).

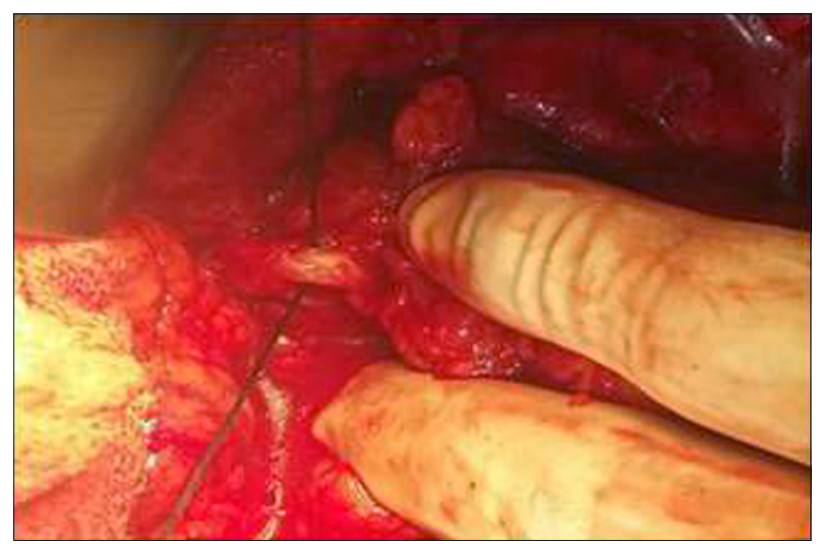

Fig. 2. Showing renal vessel being slinged with loop.

on postoperative days 3 and 5 . Three patients were discharged on postoperative day 5 and 1 on day 7. None of the patient had urinary leak or sepsis. Only 1 patient was given blood transfusion as his preoperative hemoglobin was $9.8 \mathrm{~g} \%$. Histologically all lesions were renal cell carcinoma ( 3 patients had pT1 and 1 patient had pT2) and all 4 cases

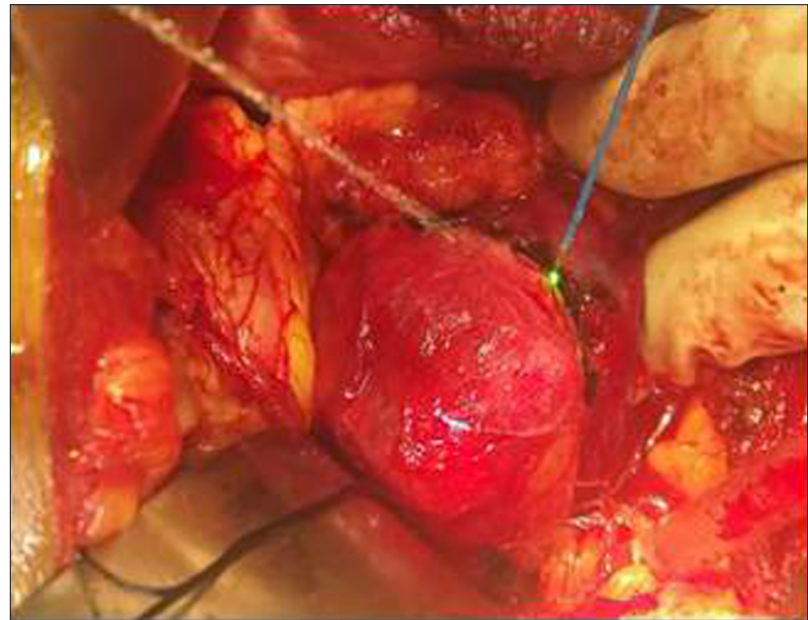

Fig. 3. Showing surface marking of the tumor done using laser fibre.



Fig. 4. Showing laser in continuous mode for cutting, gentle counter traction being given simultaneously and the field being irrigated with saline for clear vision.

showed margins negative for tumor (Tables 1, 2). During the postoperative follow-up at $1 \& 3$ months, there was no significant rise in serum creatinine. 




Fig. 5. Showing one of the steps of renorrhaphy being done.

\section{DISCUSSION}

"Zero ischemia" in partial nephrectomy is done such that tumor resection and renorrhaphy is successfully completed without hilar clamping, safeguarding the whole uninvolved kidney to ischemic stress. ${ }^{6,7}$ Warm ischemia is the most important surgically modifiable factor which governs the return of renal function postoperatively. ${ }^{5}$ Warm ischemia during partial nephrectomy is found to be associated with adverse renal consequences. ${ }^{4,7}$ Several recent studies have suggested that prolonged warm ischemia ( $>25-30$ minutes) could cause an irreversible ischemic insult to the surgically treated kidney. ${ }^{13}$ Minimally invasive partial nephrectomy done by conventional techniques using electrocautery which requires hilar clamping are criticized for longer ischemia time (warm/cold). ${ }^{5}$

Laser technologies like Diode laser and Holmium have been used in few cases reducing ischemia time. ${ }^{8,9}$ Thulium laser came into practice in 2005 and having frequency of $2013 \mathrm{~nm}$, penetration of $0.2 \mathrm{~mm}$, in continuous wave mode, offers complete absorption of energy in water. Thulium laser provides better vaporization and hemostatic properties than other lasers. ${ }^{12,13}$ Since the hemostasis is good and the operating field is clear, hence ischemia is not required.

With advent of newer technologies, it's not unusual to have increased financial burden, which can be higher than the standard open nephrectomy using mono/bipolar cautery. Thulium laser can be used for prostate surgery and also liv- er surgery which decreases the cost implication on the urologist and the hospital. Efficient and safe vascular coagulation is possible up to a vessel diameter of $1.5-2.0 \mathrm{~mm}$ hence its use is limited to only peripheral tumors as it is difficult to control large size vessels and this limits the use for deeper endophytic tumors. There are only case reports and less number of studies evaluating the use of thulium: YAG laser in renal tissues. Till date, the largest study was done on 15 patients who underwent laparoscopic partial nephrectomy. ${ }^{3}$ Thulium laser has good resection property and penetration upto 0.1 to $0.2 \mathrm{~mm}$. Hence the lateral injury is minimal. Basically, thulium laser does not cauterize the tissue; it just coagulates and cuts without damaging the tissue for histopathology examination. Carmignani et al., ${ }^{15}$ concluded that in prostatic resection the thermal effects found in the tissue are induced by coagulation both by diathermy in transurethral resection of prostate and by thulium laser in thulium laser vapo-enucleation of prostate. In histological specimens, the tissue quality was maintained after Thulium laser use, even for successive immunohistochemistry analysis. Hence it is unlikely that thulium laser will affect the histology of enucleated mass or tumor margin.

Our observation and findings have a limitation due to less number of patients; with no control group. It can be strengthened with same procedure done in more number of patients to popularize use of thulium laser in partial nephrectomy.

In conclusion, the thulium laser (Quata Cyber TM Laser system) offers good hemostasis and precise resection of the renal cortex under bloodless condition with zero ischemia time for partial nephrectomy especially for peripherally placed renal tumors. Although our study has a limitation of small pool size but still showed excellent perioperative and pathological outcomes like minimal blood loss, zero ischemia, tumor-free margins with preserved renal function in all cases.

\section{CONFLICT OF INTEREST}

The authors claim no conflicts of interest. 


\section{REFERENCES}

1. Kim JM, Song PH, Kim HT, Park TC. Comparison of partial and radical nephrectomy for pt $1 \mathrm{~b}$ renal cell carcinoma. Korean J Urol 2010;51:596-600.

2. Deng H, Fan Y, Yuan F, Wang L, Hong Z, Zhan J, et al. Partial nephrectomy provides equivalent oncologic outcomes and better renal function preservation than radical nephrectomy for pathological T3a renal cell carcinoma: a meta-analysis. Int Braz J Urol 2020 Apr 3;46 [Epub]. https://doi.org/10.1590/S1677-5538.IBJU.2020.0167.

3. Gill IS, Aron M, Gervais DA, Jewett MA. Clinical practice. Small renal mass. N Engl J Med 2010;362:62434.

4. Thompson RH, Lane BR, Lohse CM, Leibovich BC, Fergany A, Frank I, et al. Comparison of warm ischemia versus no ischemia during partial nephrectomy on a solitary kidney. Eur Urol 2010;58:331-6.

5. Rod X, Peyronnet B, Seisen T, Pradere B, Gomez FD, Verhoest $\mathrm{G}$, et al. Impact of ischaemia time on renal function after partial nephrectomy: a systematic review. BJU Int 2016;118:692-705.

6. Hou W, Ji Z. Achieving zero ischemia in minimally invasive partial nephrectomy surgery. Int J Surg 2015;18:4854.

7. Gill IS, Eisenberg MS, Aron M, Berger A, Ukimura O, Patil MB, et al. "Zero ischemia" partial nephrectomy: novel laparoscopic and robotic technique. Eur Urol 2011;59:
128-34.

8. Knezevic N, Kulis T, Maric M, Grkovic MT, Krhen I, Kastelan Z. Laparoscopic partial nephrectomy with diode laser: a promising technique. Photomed Laser Surg 2014; 32:101-5.

9. Lotan Y, Gettman MT, Ogan K, Baker LA, Cadeddu JA. Clinical use of the holmium: YAG laser in laparoscopic partial nephrectomy. J Endourol 2002;16:289-92.

10. Yunanto A, Wahyudi I, Hamid ARAH, Rodjani A. Zero ischaemia open partial nephrectomy using Thulium laser in pediatric renal tumor: a first experience. Urol Case Rep 2018;19:45-7.

11. Thomas AZ, Smyth L, Hennessey D, O'Kelly F, Moran D, Lynch TH. Zero ischemia laparoscopic partial thulium laser nephrectomy. J Endourol 2013;27:1366-70.

12. Herrmann TR, Liatsikos EN, Nagele $U$, Traxer $O$, Merseburger AS; EAU guidelines panel on lasers, technologies. EAU guidelines on laser technologies. Eur Urol 2012;61:783-95.

13. Fried NM, Murray KE. High-power thulium fiber laser ablation of urinary tissues at 1.94 microm. J Endourol 2005;19:25-31.

14. Parsons RB, Canter D, Kutikov A, Uzzo RG. RENAL nephrometry scoring system: the radiologist's perspective. AJR Am J Roentgenol 2012;199:W355-9.

15. Carmignani L, Macchi A, Ratti D, Finkelberg E, Casellato $\mathrm{S}$, Bozzini $\mathrm{G}$, et al. Are histological findings of thulium laser vapo-enucleation versus transurethral resection of the prostate comparable? Pathol Oncol Res 2015;21:1071-5. 